\title{
Cause of death and predictors of mortality in a community-based cohort of people with epilepsy
}

Mark R. Keezer, MDCM, $\mathrm{MSc}, \mathrm{FRCP}(\mathrm{C})$

Gail S. Bell, MB, ChB, MD

Aidan Neligan, PhD, MRCP

Jan Novy, MD, PhD

Josemir W. Sander, MD, $\mathrm{PhD}, \mathrm{FRCP}$

Correspondence to Dr. Sander:

l.sander@ucl.ac.uk
Editorial, page 700

Supplemental data at Neurology.org

\section{ABSTRACT}

Objective: The risk of premature mortality is increased in people with epilepsy. The reasons for this and how it may relate to epilepsy etiology remain unclear.

Methods: The National General Practice Study of Epilepsy is a prospective, community-based cohort that includes 558 people with recurrent unprovoked seizures of whom 34\% died during almost 25 years of follow-up. We assessed the underlying and immediate causes of death and their relationship to epilepsy etiology. Psychiatric and somatic comorbidities of epilepsy as predictors of mortality were scrutinized using adjusted Cox proportional hazards models.

Results: The 3 most common underlying causes of death were noncerebral neoplasm, cardiovascular, and cerebrovascular disease, accounting for 59\% (111/189) of deaths, while epilepsyrelated causes (e.g., sudden unexplained death in epilepsy) accounted for $3 \%$ (6/189) of deaths. In $23 \%$ (43/189) of individuals, the underlying cause of death was directly related to the epilepsy etiology; this was significantly more likely if death occurred within 2 years of the index seizure (percent ratio 4.28 [95\% confidence interval 2.63-6.97]). Specific comorbidities independently associated with increased risk of mortality were neoplasms (primary cerebral and noncerebral neoplasm), certain neurologic diseases, and substance abuse.

Conclusions: Comorbid diseases are important causes of death, as well as predictors of premature mortality in epilepsy. There is an especially strong relationship between cause of death and epilepsy etiology in the first 2 years after the index seizure. Addressing these issues may help stem the tide of premature mortality in epilepsy. Neurology ${ }^{\circledR}$ 2016;86:704-712

\section{GLOSSARY}

$\mathbf{C I}=$ confidence interval; $\mathbf{C O D}=$ causes of death; $\mathbf{G P}=$ general practitioner; $\mathbf{H R}=$ hazard ratio; $\mathbf{I C D}=$ International Classification of Diseases; NGPSE $=$ National General Practice Study of Epilepsy; NHS = National Health Service; PMR = proportionate mortality rate; $\mathbf{S M R}$ = standardized mortality ratio; SUDEP = sudden unexplained death in epilepsy.

Recent work has highlighted that people with epilepsy have premature mortality relative to the general population. This has been consistently shown in high-income countries such as the United Kingdom, ${ }^{1}$ United States, ${ }^{2}$ Sweden, ${ }^{3}$ and Iceland, ${ }^{4}$ as well as low- to middle-income countries such as Bolivia, ${ }^{5}$ India, ${ }^{6}$ and China. ${ }^{7}$ The reasons for this are not apparent and warrant further investigation.

Prior studies have described the distribution of causes of death (COD) in those with epilepsy but few have distinguished between underlying and immediate causes. ${ }^{7-13}$ There is a paucity of data examining the relationship between epilepsy etiology and COD. ${ }^{14,15}$ There have been attempts to describe predictors of premature mortality, including nonadherence to antiepileptic drugs, psychiatric disorders, cognitive impairment, and age, ${ }^{11,16,17}$ but there have been no comprehensive assessments of the role of the full spectrum of somatic and psychiatric comorbidities in predicting mortality in an epilepsy cohort.

We describe the underlying and immediate CODs seen in a large community-based prospective cohort of people with epilepsy with almost 25 years of follow-up and inquire into the

From NIHR University College London Hospitals Biomedical Research Centre (M.R.K., G.S.B., J.W.S.), UCL Institute of Neurology, Queen Square, London; Epilepsy Society (M.R.K., G.S.B., J.W.S.), Chalfont St Peter, Buckinghamshire; Homerton University Hospital Foundation Trust (A.N.), London, UK; Centre Hospitalier Universitaire Vaudois (CHUV) (J.N.), Lausanne, Switzerland; and Stichting Epilepsie Instellingen Nederland (SEIN) (J.W.S.), Heemstede, Netherlands.

Go to Neurology.org for full disclosures. Funding information and disclosures deemed relevant by the authors, if any, are provided at the end of the article. 
relationship between underlying COD and epilepsy etiology as well as examine for predictors of mortality, with a particular emphasis on somatic and psychiatric comorbidities.

METHODS The National General Practice Study of Epilepsy (NGPSE) is a longitudinal cohort study of people with incident epileptic seizures, the methods of which have been described previously. ${ }^{1,18}$ Participants were initially identified between June 1984 and October 1987 by 275 participating general practitioners (GPs) from across the United Kingdom who were asked to report any person of any age with newly suspected epileptic seizures. A diagnostic panel reviewed all potential participants and identified those with definite or probable epileptic seizures. Of the initial 1,195 people registered, 792 (66.3\%) had had epileptic seizures. The remaining individuals were diagnosed with febrile seizures $(n=220)$, previously diagnosed epilepsy or neonatal seizures $(n=104)$, or no clear history of epileptic seizures $(n=79)$.

For the purposes of this report, we excluded those with a single recorded seizure and those with acute symptomatic seizures (i.e., occurring within 90 days of a precipitating cerebral injury). This resulted in 558 individuals with recurrent unprovoked epileptic seizures, i.e., epilepsy. ${ }^{19}$

The initial round of data collection carried out between 1984 and 1987 elicited data on basic demographics and clinical characteristics. Additional information was sought on all possible somatic and psychiatric comorbidities. This final set of queries used pointed (i.e., requiring an affirmative or negative response) and open-ended questions (i.e., requiring a free-text response), instructing GPs to record any additional conditions the individual may have. There were a total of 12 rounds of data collection on participant comorbidities, up until 2001. Following this, after the passage of the UK Data Protection Act of $1998^{20}$ and the Health and Social Care Act of 2001, ${ }^{21}$ the collection of comorbidity data was expressly not allowed during the 2009 follow-up. A single study author (M.R.K.) reviewed the reported comorbidities and coded the associated ICD-10 chapter $^{22}$ and the date when it was first reported. The 10th version of the ICD is a system developed and supported by the WHO that classifies human disease into 20 different categories. Comorbidities that were only listed on the death certificates were not included in this analysis as this would have created a bias differential to those who have died.

All individuals in the NGPSE have been flagged at the UK National Health Service (NHS) Information Centre and the investigators are sent a copy of the death certificate whenever a person dies. This ensures complete mortality ascertainment, assuming that the participant dies within the territorial boundaries of the United Kingdom or that the NHS was notified of the death if the participant died elsewhere. Each death certificate respects the WHO's recommended format and includes fields for recording up to 3 CODs as well as field II (i.e., "Other significant conditions contributing to the death"). ${ }^{23}$ We included all deaths occurring up until October 5, 2009, in this report.

Only selected data related to the distribution of CODs from the NGPSE have been reported. ${ }^{1,24,25}$ Previously we identified one primary COD based upon the clinical judgment of the investigators, frequently using the first condition described on the death certificate. Now we present complete COD data and strictly distinguish between underlying $\mathrm{COD}$ and immediate COD. The distinction between these 2 types of COD reflects which condition initiated a series of events leading to death (i.e., the underlying COD) vs the condition that occurred only just prior to death (i.e., immediate COD). The Sixth Decennial International Revision Conference of the WHO resolved that the underlying COD be reported as the main COD in all official reporting. ${ }^{23,26}$ Care was taken to record the underlying COD according to the General Principle and selection rules as laid out in the ICD-10 manual. ${ }^{23}$ As such, pneumonia and pulmonary embolism were considered immediate CODs unless there were no other CODs listed on the death certificate, in which case they were recorded as "pneumonia or pulmonary embolism not otherwise specified." Cardiac or respiratory failure is a mode of death and not a $\mathrm{COD}^{23}$; if no other condition was listed on the death certificate, the underlying and immediate CODs were coded as "Other." Vascular dementia was coded as dementia rather than cerebrovascular disease. Each COD was described as a proportionate mortality rate (PMR), where the numerator was the number of deaths due to a particular COD and the denominator the total number of deaths within the NGPSE. ${ }^{27}$

The underlying epilepsy etiology was characterized for all individuals. This was done using data provided by GPs up until the timing of the diagnostic panel. One study author (M.R.K.), unaware of any other characteristic of each person, including the timing of death, determined whether the underlying COD was directly related to the epilepsy etiology for that individual (e.g., due to a primary cerebral neoplasm or to cerebrovascular disease). Death from an external cause was generally not considered related to post-traumatic epilepsy unless these were the same event.

Statistical analyses. Differences in proportions were tested using 2-sided Fisher exact test. A Holms-Bonferroni correction was used to control for the effect of multiple comparisons. ${ }^{28}$

Cox proportional hazards regression was used to model associations between each ICD comorbidity chapter and all-cause mortality. Each ICD chapter was first regressed using a simple model where age (categorized into approximate quartiles) at the time of the index seizure (the event that led to presenting to medical attention) and sex were included as covariates. ICD chapters found to have a $p<0.10$ in the simple model were included in the fully adjusted model, along with age at the time of the index seizure, participant sex, and early epilepsy remission (defined as an absence of seizures more than 1 year after the index event). The period at risk for each participant began with the time of the index seizure and ended with the time of death or, if alive, October 5, 2009. With the exception of ICD chapters 16 and 17 , which are by definition congenital, each ICD chapter was treated as a categorically time-varying covariate with the exposure beginning when it was first reported to the NGPSE investigators. Schoenfeld residuals were used to confirm the proportionality assumption in the fully adjusted regression models. ${ }^{29}$

We used additional regression models to investigate the individual comorbid conditions contained within those ICD chapters that were significant predictors of all-cause mortality (in the fully adjusted ICD chapter models) as well as those that were of particular clinical interest (e.g., all neurologic and psychiatric diseases). Simple and fully adjusted regression models were carried out in a similar manner to that for the ICD chapters.

STATA/SE, version 12.0 (StataCorp LP, College Station, TX) was used to conduct all statistical analyses.

Standard protocol approvals, registrations, and patient consents. The NGPSE was approved by the National Research Ethics Committee (reference 07/H0720/160) and the National Information Governance Board Ethics and Confidentiality Committee (PIAF 1-05 [g]/2008 NGPSE). The requirement for individual participant consent was waived. 


\begin{tabular}{|c|c|c|}
\hline Table 1 & \multicolumn{2}{|c|}{$\begin{array}{l}\text { Study participant characteristics } \\
(\mathrm{n}=558)\end{array}$} \\
\hline \multicolumn{2}{|c|}{ Characteristics } & Values $^{a}$ \\
\hline \multicolumn{2}{|l|}{ Male sex } & 291 (52) \\
\hline \multicolumn{3}{|c|}{ Epilepsy etiology } \\
\hline \multicolumn{2}{|c|}{ Remote symptomatic } & $132(24)$ \\
\hline \multicolumn{2}{|c|}{ Idiopathic/cryptogenic } & $426(76)$ \\
\hline \multicolumn{2}{|c|}{ Early epilepsy remission ${ }^{b}$} & 183 (33) \\
\hline \multicolumn{2}{|c|}{ All-cause mortality } & $190(34)^{c}$ \\
\hline \multicolumn{3}{|c|}{ Age at index seizure, $y$} \\
\hline \multicolumn{2}{|c|}{ Entire cohort } & $24.4(13.8-56.1)^{d}$ \\
\hline \multicolumn{2}{|l|}{ Alive } & $17.1(9.6-27.4)$ \\
\hline \multicolumn{2}{|l|}{ Dead } & $64.2(50.8-75.1)$ \\
\hline \multicolumn{3}{|c|}{ Age at last follow-up, y } \\
\hline \multicolumn{2}{|c|}{ Entire cohort } & $47.4(36.8-70.9)$ \\
\hline \multicolumn{2}{|l|}{ Alive } & 40.9 (33.3-51.1) \\
\hline \multicolumn{2}{|l|}{ Dead } & $74.8(59.1-83.1)$ \\
\hline \multicolumn{3}{|c|}{ Duration of follow-up, $y$} \\
\hline \multicolumn{2}{|c|}{ Entire cohort } & $23.0(14.9-24.2)$ \\
\hline \multicolumn{2}{|l|}{ Alive } & $23.9(23.0-24.7)$ \\
\hline \multicolumn{2}{|l|}{ Dead } & $8.1(2.3-15.2)$ \\
\hline
\end{tabular}

a Variables presented as $\mathrm{n}(\%)$ or median (interquartile range).

${ }^{b}$ Defined as no recurrent seizures more than 1 year after the index event.

${ }^{\mathrm{C}}$ One death certificate was missing and so this individual was excluded from the cause of death-related analyses.

${ }^{d}$ Thirty-eight percent of individuals (212/558) were younger than 18 years.

RESULTS The clinical characteristics and demographics of the cohort are presented in table 1 . There were 190 deaths during the follow-up period although the death certificate for one person was not available (who was therefore excluded from the COD-related analyses).

The distribution of underlying CODs is depicted in figure 1A. A majority of deaths were due to noncerebral neoplasm, cardiovascular disease, or cerebrovascular disease $(58.7 \%$ or $111 / 189)$, while external causes $(4.2 \%$ or $8 / 189)$ and epilepsy-related causes (e.g., sudden unexplained death in epilepsy [SUDEP] or status epilepticus) $(3.2 \%$ or $6 / 189)$ accounted for a minority. Twenty-nine percent (12/41) of the fatal noncerebral neoplasms were responsible for an individual's epilepsy as a result of metastatic disease. Underlying CODs within the "other" category included chronic alcoholism, hepatic encephalopathy, diabetes mellitus, hypertension, systemic amyloidosis, endocarditis, nephropathy, peripheral vascular disease, and ischemic bowel disease.

The distribution of immediate CODs is shown in figure 1B. Pneumonia was the most common immediate
COD $(31.2 \%$ or $59 / 189)$. Among individuals whose immediate COD was pneumonia, the underlying CODs were cerebrovascular disease (22.0\% [13/59]), other (17\% [10/59]), noncerebral neoplasm $(13.6 \%$ [8/59]), congenital neurologic disorder (11.9\% [7/59]), cardiovascular disease (8.5\% [5/59]), neurodegenerative disease $(8.5 \%[5 / 59])$, and epilepsy-related (3.4\% [2/59]). Among 9 (4.8\%) individuals who died of pneumonia, an underlying COD was not indicated on the death certificate.

There were no evident differences in the proportions of each underlying COD when stratified by timing of death ( $\leq 2$ years vs $>2$ years after the index seizure) (table e-1 on the Neurology ${ }^{\circledR}$ Web site at Neurology. org). People age 60 years or younger at the time of the index seizure as well as those age 60 years or younger at the time of death were more likely to die of primary cerebral neoplasm $(15.1 \%$ vs $0.9 \%, p<0.011$, and 21 . $3 \%$ vs $1.4 \%, p<0.011$, respectively) but were less likely to die of cerebrovascular disease $(2.7 \%$ vs 26 . $7 \%, p<0.011$, and $4.3 \%$ vs $21.8 \%, p<0.032$, respectively) (table e-1). People age 60 years or younger at the time of death were also more likely to die of external causes $(12.8 \%$ vs $1.4 \%, p=0.03)$ or a congenital neurologic disorder $(12.8 \%$ vs $1.4 \%, p=0.03)$.

We found that in $22.8 \%(43 / 189)$ of deaths, the underlying COD was directly related to the individual's epilepsy etiology. This proportion was as high as $57.5 \%$ during the first 2 years of follow-up, decreasing to $6.0 \%$ after $>15$ years of follow-up (figure 2, with further details in table e-2). Overall, among people dying within 2 years of their index seizure, there was a more than fourfold greater chance that the cause of their epilepsy was directly related to their underlying COD (percent ratio 4.28, 95\% confidence interval $[\mathrm{CI}] 2.63-6.97 ; p<0.0001)$ as compared to people who died more than 2 years after their index seizure. The epilepsy etiologies of the 189 individuals who died are listed in table e-3.

The results of our survival analyses examining for predictors of mortality are presented in tables 2 and 3 . Male sex was found to be protective, with a roughly $30 \%$ decrease in the risk of death (adjusted hazard ratios [HRs] 0.69 and 0.70 ). Early epilepsy remission was also protective (adjusted HRs 0.61 and 0.66 ).

Of the comorbidities of epilepsy, ICD chapters 2 (neoplasms), 4 (endocrine, nutritional, and metabolic diseases), 13 (diseases of the musculoskeletal system and connective tissue), 17 (congenital malformations, deformations, and chromosomal abnormalities), and 19/20 (injury, poisoning, and certain other consequences of external causes/external causes of morbidity and mortality) were significant predictors of mortality (table 2). ICD chapter 13 was the only chapter whose presence predicted a decreased risk of mortality (adjusted HR 0.42 [95\% CI 0.19-0.91]). 


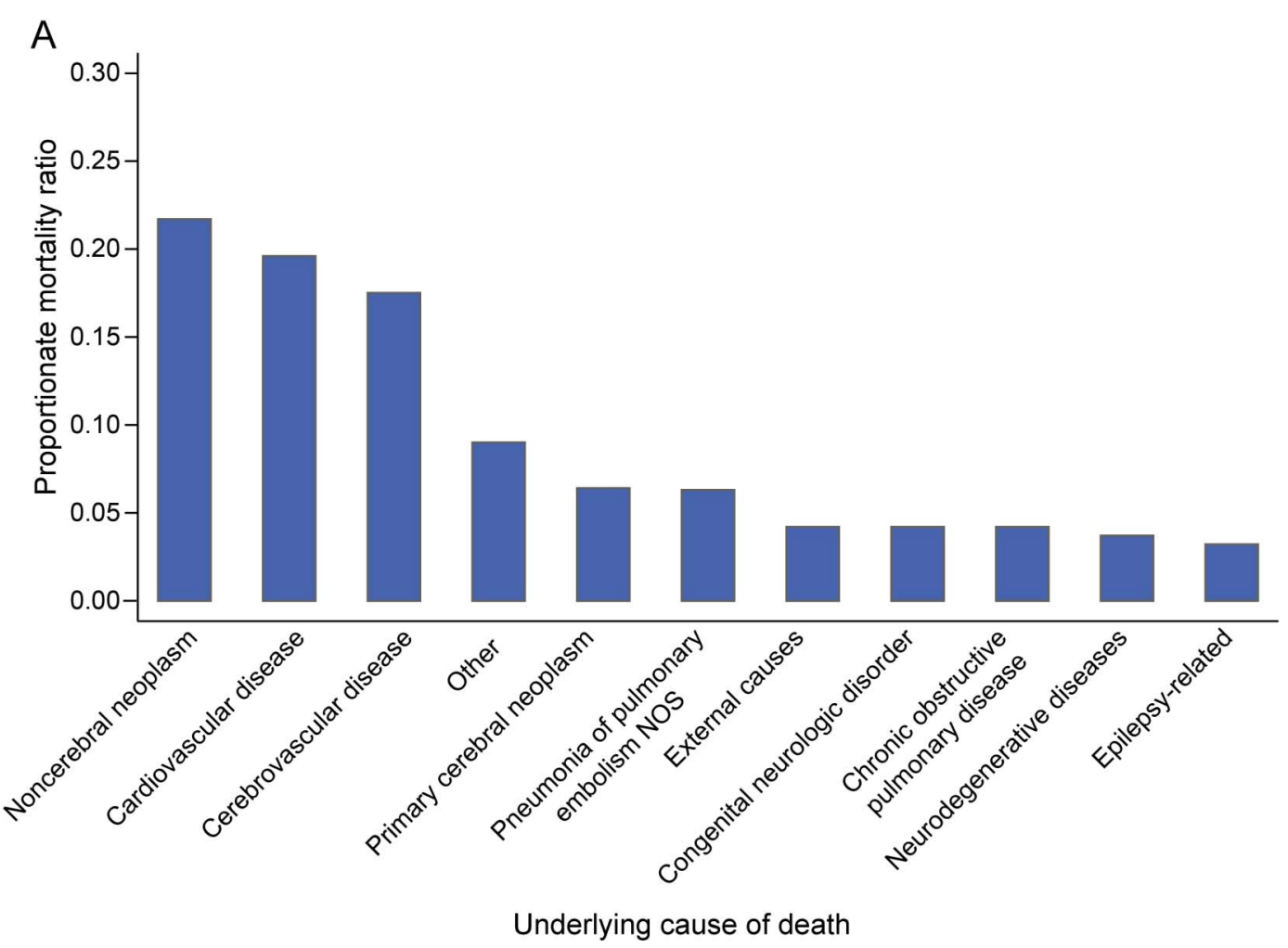

B

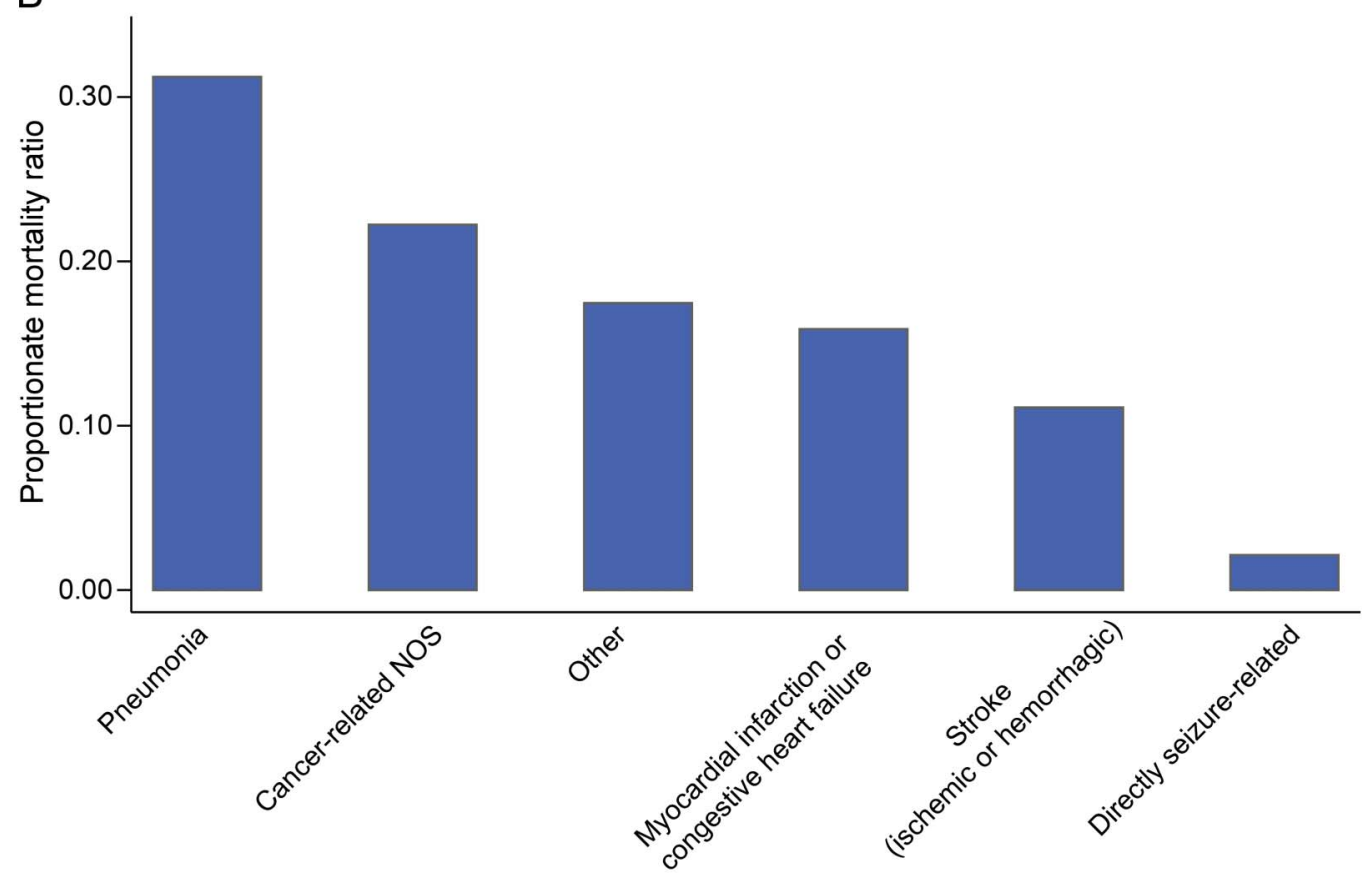

Immediate cause of death

NOS $=$ not otherwise specified

Examining the constituents of selected ICD chapters, primary cerebral and noncerebral neoplasms, dementia, Parkinson disease, cerebrovascular disease, traumatic brain injury, and substance abuse were significant and independent predictors of mortality (table 3).
DISCUSSION The NGPSE is one of the largest prospective community-based cohorts with almost 25 years follow-up examining the risk and determinants of mortality among people with epilepsy., ${ }^{2,30}$ Prior analyses of the NGPSE have reported the overall standardized mortality ratio (SMR) for all-cause 
Figure 2 Relationship between epilepsy etiology and underlying cause of death (COD)

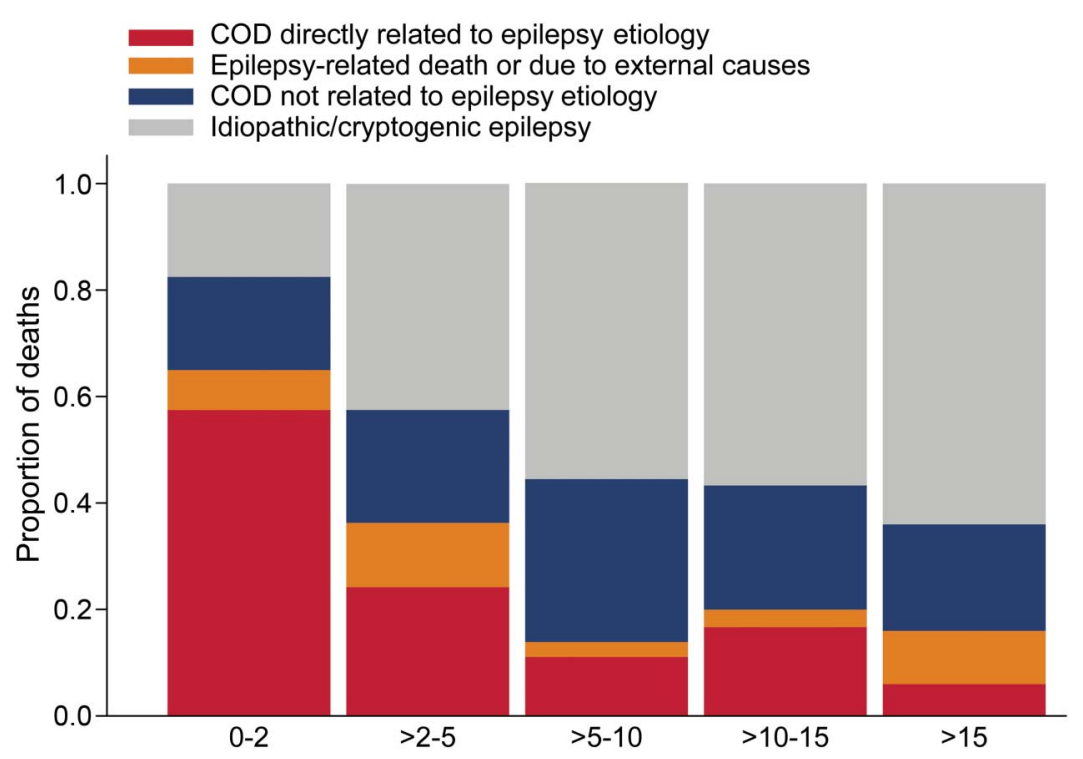

Number of years between index seizure and death

mortality, stratified by age, timing after the index seizure, and epilepsy etiology, as well as SMRs for selected CODs. ${ }^{1,24,25}$ In this article, we report 3 novel main findings. First, we describe the complete distribution of CODs, distinguish between underlying and immediate CODs, and demonstrate that the majority of deaths $(59 \%)$ were due to noncerebral neoplasms (only 29\% of which were related to the epilepsy etiology), cardiovascular disease, and cerebrovascular disease, while epilepsy-related causes accounted for only $3 \%$ of deaths. Pneumonia was the most important immediate COD, representing what is likely a common terminus in a fatal sequence of events. Second, we demonstrate that overall $23 \%$ of underlying CODs were directly related to an individual's epilepsy etiology and that this was fourfold as likely to be the case if death occurred within 2 years of the index seizure. Third, we demonstrate that several somatic and psychiatric comorbidities are predictive of mortality. When examining specific conditions, neoplasms (primary cerebral and noncerebral neoplasm), several neurologic diseases (dementia, Parkinson disease, cerebrovascular disease, and traumatic brain injury), and substance abuse were independently associated with increased mortality risk.

The majority of deaths in our cohort were due to noncerebral neoplasms, cardiovascular disease, and cerebrovascular disease, while relatively few were epilepsy-related. It is difficult to compare PMRs between populations but our findings are generally comparable to others in high-income countries. A previous meta-analysis reported that $4 \%$ of deaths in low-risk groups of people with epilepsy are due to SUDEP $^{31}$ (generally considered to be the most common cause of epilepsy-related death). ${ }^{32}$ Our findings emphasize that comorbidities similar to those responsible for mortality in the general population ${ }^{33}$ are also the most important mediators of premature death in people with epilepsy. The increased risk of mortality from these diseases may be related to the postulated proneoplastic effect of certain antiepileptic drugs $^{1}$ or the increased risk of metabolic syndrome with others. ${ }^{34}$ It may also be that epilepsy is a surrogate in some instances for severe neoplastic or atherosclerotic disease, where individuals with more severe forms of these comorbidities are more likely to develop epilepsy as well as die prematurely. In either case, at the level of the general population, physician counseling of people with epilepsy with regards to neoplastic and atherosclerotic risk factors appears to be as important as counseling individuals on the risk of SUDEP or status epilepticus, if not more so.

Only one other study has investigated the relationship between epilepsy etiology and COD, showing that in the first year of follow-up, $72.2 \%$ (39/54) of CODs among those with remote symptomatic epilepsy were related to the underlying epilepsy etiology. ${ }^{14}$ We now confirm these findings, doing so with a much larger cohort than the previous investigators. We additionally demonstrate that this relationship between underlying COD and epilepsy etiology weakens over time, which may explain why mortality rates similarly decrease over time. ${ }^{1}$

We report a number of comorbid conditions that significantly and independently predict mortality in the NGPSE. One recent study reported that a lifetime history of certain psychiatric disorders (including substance abuse) predicted increased risk of death from external causes (largely suicide and accidental death). ${ }^{11}$ We now demonstrate that a lifetime history of substance abuse is a significant predictor of not only death due to external causes but all-cause mortality.

Our findings show that male sex was associated with a $30 \%$ decrease in mortality risk, after controlling for age, early epilepsy remission, and comorbidities. This is somewhat surprising as male sex is typically associated with a shorter life expectancy. ${ }^{35}$ This merits further study.

Our study has a number of strengths. The NGPSE is a prospective community-based cohort of people with both adult and childhood-onset epilepsy, allowing for a complete spectrum of people, and has an exceptionally long period of follow-up. Our method of assessing whether an individual has died or not probably captured all deaths. Finally, we carefully defined underlying and immediate COD for each participant (using the official death certificate but generally without the benefit of an autopsy), 


\section{Predictor}

Age at index seizure, y

$$
\begin{aligned}
& <15(n=161) \\
& 15 \text { to }<30(n=152) \\
& 30 \text { to }<60(n=123) \\
& \geq 60(n=122) \\
& \text { Male sex }(n=291)
\end{aligned}
$$$$
\text { Early epilepsy remission }{ }^{d}(n=183)
$$$$
\text { ICD-10 } \text { chapters }^{\mathrm{e}}
$$

1: Certain infectious and parasitic diseases $(n=11)$

$$
\text { 2: Neoplasms }(n=55)
$$

3: Diseases of the blood and blood-forming organs and certain disorders involving the immune mechanism $(n=15)$

4: Endocrine, nutritional, and metabolic diseases $(n=41)$

5: Mental and behavioral disorders $(n=135)$

6: Diseases of the nervous system $(n=83)$

7: Diseases of the eye and adnexa $(n=12)$

8: Diseases of the ear and mastoid process $(n=9)$

9: Diseases of the circulatory system $(n=119)$

10: Diseases of the respiratory system $(n=54)$

11: Diseases of the digestive system $(n=37)$

12: Diseases of the skin and subcutaneous tissue $(n=26)$

13: Diseases of the musculoskeletal system and connective tissue $(n=32)$

14: Diseases of the genitourinary system $(n=18)$

15: Pregnancy, childbirth, and the puerperium $(n=7)$

16: Certain conditions originating in the perinatal period $(n=10)$

17: Congenital malformations, deformations, and chromosomal abnormalities $(n=13)$

\begin{tabular}{|c|c|c|c|}
\hline & \\
\hline Hazard ratio (95\% Cl) & p Value & Hazard ratio $(95 \% \mathrm{Cl})$ & p Value \\
\hline Reference & - & Reference & - \\
\hline $1.56(0.67-3.66)$ & 0.302 & $1.74(0.74-4.10)$ & 0.206 \\
\hline $9.55(4.70-19.39)^{c}$ & $<0.001^{\mathrm{c}}$ & $10.48(5.09-21.56)^{c}$ & $<0.001^{\mathrm{c}}$ \\
\hline $52.69(26.46-104.92)^{c}$ & $<0.001^{\mathrm{c}}$ & $67.98(33.09-139.64)^{c}$ & $<0.001^{\mathrm{c}}$ \\
\hline $0.77(0.58-1.03)$ & 0.077 & $0.69(0.51-0.92)^{c}$ & $0.013^{c}$ \\
\hline $0.73(0.53-1.00)^{c}$ & $0.047^{c}$ & $0.61(0.44-0.83)^{\mathrm{c}}$ & $0.002^{c}$ \\
\hline $1.62(0.22-11.88)$ & 0.633 & & \\
\hline $3.05(1.67-5.57)^{\mathrm{c}}$ & $<0.001^{c}$ & $2.72(1.47-5.04)^{c}$ & $0.001^{c}$ \\
\hline $1.36(0.60-3.11)$ & 0.461 & & \\
\hline $3.10(1.54-6.21)^{c}$ & $0.001^{c}$ & $3.36(1.65-6.82)^{c}$ & $0.001^{c}$ \\
\hline $1.19(0.77-1.83)$ & 0.429 & & \\
\hline $1.29(0.68-2.46)$ & 0.437 & & \\
\hline $0.47(0.11-1.90)$ & 0.286 & & \\
\hline$N A^{f}$ & - & & \\
\hline $1.09(0.68-1.75)$ & 0.710 & & \\
\hline $1.27(0.59-2.73)$ & 0.539 & & \\
\hline $1.49(0.82-2.71)$ & 0.188 & & \\
\hline $1.10(0.27-4.48)$ & 0.893 & & \\
\hline $0.46(0.21-0.99)^{c}$ & $0.048^{c}$ & $0.41(0.19-0.88)^{c}$ & $0.022^{c}$ \\
\hline $1.09(0.40-2.95)$ & 0.872 & & \\
\hline$N A^{f}$ & - & & \\
\hline $3.35(0.78-14.4)$ & 0.105 & & \\
\hline $4.84(1.92-12.18)^{c}$ & $0.001^{c}$ & $5.20(2.06-13.16)^{c}$ & $<0.001^{c}$ \\
\hline $1.84(0.68-4.97)$ & 0.229 & & \\
\hline $2.62(1.21-5.69)^{c}$ & $0.015^{c}$ & $2.67(1.21-5.92)^{c}$ & $0.015^{c}$ \\
\hline
\end{tabular}

18: Symptoms, signs, and abnormal clinical and laboratory findings, not elsewhere classified $(n=13)$

19/20: Injury, poisoning, and certain other consequences of external causes/external causes of morbidity and mortality $(n=45)$
Simple models ${ }^{a}$

Abbreviation: $\mathrm{Cl}=$ confidence interval.

all models included age at index seizure and sex as covariates.

${ }^{b}$ This model also included early epilepsy remission as well as any ICD-10 chapter that was found to have a $p<0.10$ in the simple models.

c Significant.

${ }^{d}$ Defined as no recurrent seizures more than 1 year after the index event.

e ICD-10, classifying human disease into 20 broad categories.

${ }^{f}$ Not available; could not be calculated due to collinearity.

while following rules as described by the WHO, which is an important distinction if one's ultimate goal is to interrupt the fatal sequence of events leading to death. ${ }^{23}$

Our study has limitations. The NGPSE relied upon GP reporting of psychiatric and somatic comorbidities, via a combination of pointed and openended questions. These data were sampled on 12 occasions, up to 2001, after which no further comorbidity information could be collected. We expect that misclassification of each participant's comorbidity status (including failure to report an existing comorbidity) was probably independent of their eventual survival outcome. As a result, any bias would have led to an underestimation rather than an overestimation of the associated risk, and therefore any significant findings are likely to be true. The NGPSE also relied upon the history and records 


\begin{tabular}{|c|c|c|c|c|}
\hline Predictor & \multicolumn{2}{|l|}{ Simple models ${ }^{a}$} & \multicolumn{2}{|l|}{ Fully adjusted model ${ }^{a, b}$} \\
\hline \multicolumn{5}{|l|}{ Age at index seizure, $y$} \\
\hline$<15(n=161)$ & Reference & - & Reference & - \\
\hline 15 to $<30$ ( $n=152)$ & $1.56(0.67-3.66)$ & 0.302 & $1.95(0.81-4.65)$ & 0.134 \\
\hline 30 to $<60(n=123)$ & $9.55(4.70-19.39)^{c}$ & $0.001^{c}$ & $11.16(5.31-23.45)^{c}$ & $<0.001^{\mathrm{c}}$ \\
\hline Male sex $(n=291)$ & $0.77(0.58-1.03)$ & 0.077 & $0.70(0.52-0.95)^{c}$ & $0.021^{c}$ \\
\hline Early epilepsy remission $(n=183$ ) & $0.73(0.53-1.00)^{c}$ & $0.047^{c}$ & $0.66(0.48-0.93)^{c}$ & $0.016^{c}$ \\
\hline \multicolumn{5}{|l|}{ ICD chapter $2^{d}$} \\
\hline Primary cerebral neoplasm $(n=22)$ & $4.36(2.65-7.17)^{c}$ & $<0.001^{\mathrm{c}}$ & $5.02(2.99-8.43)^{c}$ & $<0.001^{\mathrm{c}}$ \\
\hline \multicolumn{5}{|l|}{ ICD chapter 4} \\
\hline Other $(n=14)$ & $2.77(1.11-6.95)^{\mathrm{c}}$ & $0.029^{c}$ & $2.12(0.68-6.58)$ & 0.194 \\
\hline \multicolumn{5}{|l|}{ ICD chapter 5} \\
\hline Depression $(n=42)$ & $0.55(0.26-1.19)$ & 0.131 & & \\
\hline Anxiety $(n=11)$ & $1.09(0.26-4.46)$ & 0.909 & & \\
\hline Substance abuse $(n=27)$ & $3.63(1.33-9.88)^{c}$ & $0.012^{c}$ & $5.42(1.92-15.26)^{c}$ & $0.001^{c}$ \\
\hline Dementia $(n=41)$ & $2.30(1.32-4.00)^{c}$ & $0.003^{c}$ & $2.75(1.51-5.01)^{c}$ & $0.001^{c}$ \\
\hline Learning disability $(\mathrm{n}=22)$ & $2.58(1.11-6.03)^{c}$ & $0.028^{c}$ & $2.10(0.86-5.12)$ & 0.104 \\
\hline Other $(n=20)$ & $1.65(0.21-12.88)$ & 0.630 & & \\
\hline \multicolumn{5}{|l|}{ ICD chapter 6} \\
\hline \multicolumn{5}{|l|}{ ICD chapter 9} \\
\hline Cerebrovascular disease $(n=53)$ & $2.93(1.47-5.83)^{\mathrm{c}}$ & $0.002^{c}$ & $3.96(1.96-8.04)^{c}$ & $<0.001^{\mathrm{c}}$ \\
\hline Cardiac disease $(n=45)$ & $1.13(0.65-1.96)$ & 0.674 & & \\
\hline Hypertension $(n=37)$ & $1.10(0.44-2.74)$ & 0.843 & & \\
\hline Other $(n=20)$ & $1.46(0.68-3.14)$ & 0.9184 & & \\
\hline \multicolumn{5}{|l|}{ ICD chapter 13} \\
\hline Inflammatory musculoskeletal disease $(n=14)$ & $0.23(0.03-1.62)$ & 0.139 & & \\
\hline Degenerative musculoskeletal disease $(n=13)$ & $0.55(0.22-1.35)$ & 0.190 & & \\
\hline Other $(n=5)$ & $0.94(0.13-6.80)$ & 0.951 & & \\
\hline \multicolumn{5}{|l|}{ ICD chapter 17} \\
\hline $\begin{array}{l}\text { Congenital malformations, deformations, and chromosomal } \\
\text { abnormalities }(n=13)\end{array}$ & $4.84(1.92-12.18)^{\mathrm{c}}$ & $0.001^{c}$ & $4.89(1.85-12.87)^{\mathrm{c}}$ & $0.001^{c}$ \\
\hline \multicolumn{5}{|l|}{ ICD chapter $19 / 20$} \\
\hline Traumatic brain injury $(n=32)$ & $5.67(1.34-23.98)^{\mathrm{c}}$ & $0.018^{c}$ & $9.80(2.30-41.68)^{\mathrm{c}}$ & $0.002^{c}$ \\
\hline Any fracture without brain injury $(n=9)$ & $2.52(0.92-6.90)$ & 0.073 & $2.06(0.71-5.95)$ & 0.182 \\
\hline Other $(n=4)$ & $1.27(0.17-9.22)$ & 0.816 & & \\
\hline
\end{tabular}

Abbreviation: $\mathrm{Cl}=$ confidence interval.

${ }^{a}$ All models included age at index seizures and sex as covariates.

${ }^{\mathrm{b}}$ This model also included early epilepsy remission as well as any comorbidity that was found to have a $p<0.10$ in the simple models.

c Significant.

${ }^{d}$ The number with each comorbidity will not necessarily equate with those numbers presented in table 2, given that a single individual may have more than one comorbidity within each chapter. 
provided by GPs in the 1980s to establish the etiology of each person's epilepsy without the benefit of modern imaging techniques. This inevitably means that some individuals labeled as having cryptogenic epilepsy would have a declared etiology if the study were repeated today. Practically speaking, however, the repetition of such a study seems remote given the current research environment and requirements for individual consent, at least in the United Kingdom.

This study presents a number of important findings related to improving our understanding of the determinants of premature mortality in epilepsy. These findings represent important opportunities for future research and potential avenues for preventative strategies and initiatives.

\section{AUTHOR CONTRIBUTIONS}

M.R.K., G.S.B., and J.W.S. designed the study. M.R.K., A.N., G.S.B., and J.N. collected the data. M.R.K. carried out the statistical analyses and drafted the manuscript. M.R.K., G.S.B., A.N., J.N., and J.W.S. critically revised the manuscript. All approved the final version. J.W.S. is the guarantor.

\section{ACKNOWLEDGMENT}

The authors thank all previous members of the NGPSE team, in particular Professor Simon Shorvon, Dr. David Goodridge, and Dr. Tony Johnson; and all of the GPs who helped with the NGPSE over the years.

\section{STUDY FUNDING}

M.R.K. is supported by a student award from the Fonds de recherche Québec-santé (Canada). J.W.S. receives research support from the Dr. Marvin Weil Epilepsy Research Fund. This work was undertaken at the UCLH/UCL Comprehensive Bio-Medical Research Centre, which received a proportion of its funding from the Department of Health's NIHR Biomedical Research Centres funding scheme. The listed funding agencies played no role in the design and conduct of the study; collection, management, analysis, or interpretation of the data; or preparation, review, or approval of the manuscript

\section{DISCLOSURE}

M. Keezer reports grants and personal fees from UCB, outside the submitted work. G. Bell's husband previously worked for GlaxoSmithKline, while she and her husband hold company shares in GSK. A. Neligan has received a speaking honorarium from Eisai. J. Novy has received travel and speaker honoraria from Pfizer and UCB. J. Sander has received research funding from Eisai, GSK, and UCB, AND personal fees from Eisai, UCB, Lundbeck, and Teva, outside the submitted work. He receives research support from the Marvin Weil Epilepsy Research Fund. His current position is endowed by the Epilepsy Society, and he is a member of the editorial board of Lancet Neurology. Go to Neurology.org for full disclosures.

Received June 25, 2015. Accepted in final form October 13, 2015.

\section{REFERENCES}

1. Neligan A, Bell GS, Johnson AL, Goodridge DM, Shorvon SD, Sander JW. The long-term risk of premature mortality in people with epilepsy. Brain 2011;134:388-395.

2. Hauser WA, Annegers JF, Elveback LR. Mortality in patients with epilepsy. Epilepsia 1980;21:399-412.

3. Lindsten H, Nystrom L, Forsgren L. Mortality risk in an adult cohort with a newly diagnosed unprovoked epileptic seizure: a population-based study. Epilepsia 2000;41: 1469-1473.
4. Olafsson E, Hauser WA, Gudmundsson G. Long-term survival of people with unprovoked seizures: a populationbased study. Epilepsia 1998;39:89-92.

5. Nicoletti A, Sofia V, Vitale G, et al. Natural history and mortality of chronic epilepsy in an untreated population of rural Bolivia: a follow-up after 10 years. Epilepsia 2009;50: 2199-2206.

6. Carpio A, Bharucha NE, Jallon P, et al. Mortality of epilepsy in developing countries. Epilepsia 2005;46(suppl 11):28-32.

7. Ding D, Wang W, Wu J, et al. Premature mortality risk in people with convulsive epilepsy: long follow-up of a cohort in rural China. Epilepsia 2013;54:512-517.

8. Nevalainen O, Raitanen J, Ansakorpi H, Artama M, Isojarvi J, Auvinen A. Long-term mortality risk by cause of death in newly diagnosed patients with epilepsy in Finland: a nationwide register-based study. Eur J Epidemiol 2013;28:981-990.

9. Mu J, Liu L, Zhang Q, et al. Causes of death among people with convulsive epilepsy in rural West China: a prospective study. Neurology 2011;77:132-137.

10. Nilsson L, Tomson T, Farahmand BY, Diwan V, Persson PG. Cause-specific mortality in epilepsy: a cohort study of more than 9,000 patients once hospitalized for epilepsy. Epilepsia 1997;38:1062-1068.

11. Fazel S, Wolf A, Langstrom N, Newton CR, Lichtenstein P. Premature mortality in epilepsy and the role of psychiatric comorbidity: a total population study. Lancet 2013;382: 1646-1654.

12. Forsgren L, Hauser WA, Olafsson E, Sander JW, Sillanpaa M, Tomson T. Mortality of epilepsy in developed countries: a review. Epilepsia 2005;46:18-27.

13. Lhatoo SD, Sander JW. Cause-specific mortality in epilepsy. Epilepsia 2005;46(suppl 11):36-39.

14. Loiseau J, Picot MC, Loiseau P. Short-term mortality after a first epileptic seizure: a population-based study. Epilepsia 1999;40:1388-1392.

15. Shackleton DP, Westendorp RG, Trenite DG, Vandenbroucke JP. Mortality in patients with epilepsy: 40 years of follow up in a Dutch cohort study. J Neurol Neurosurg Psychiatry 1999;66:636-640.

16. Ngugi AK, Bottomley C, Fegan G, et al. Premature mortality in active convulsive epilepsy in rural Kenya: causes and associated factors. Neurology 2014;82:582-589.

17. Faught E, Duh MS, Weiner JR, Guerin A, Cunnington MC. Nonadherence to antiepileptic drugs and increased mortality: findings from the RANSOM Study. Neurology 2008;71: 1572-1578.

18. Hart YM, Sander JW, Sharvon SD. National General Practice Study of Epilepsy and Epileptic Seizures: objectives and study methodology of the largest reported prospective cohort study of epilepsy: National General Practice Study of Epilepsy and Epileptic Seizures (NGPSE). Neuroepidemiology 1989;8:221-227.

19. Thurman DJ, Beghi E, Begley CE, et al. Standards for epidemiologic studies and surveillance of epilepsy. Epilepsia 2011;52:2-26.

20. UK Parliament Acts. European Data Protection Act 1998. Available at: http://www.legislation.gov.uk/ukpga/1998/ 29/contents/enacted. Accessed May 25, 2015.

21. British Parliament. Health and Social Care Act 2001. Available at: http://www.legislation.gov.uk/ukpga/2001/ 15/pdfs/ukpga_20010015_en.pdf. Accessed May 22, 2015 . 
22. World Health Organization. International Classification of Diseases-10 version: 2010. Available at: http://apps.who.int/ classifications/icd10/browse/2010/en. Accessed June 6, 2014.

23. Mortality: Guidelines for Certification and Rules for Coding. In: International Statistical Classification of Diseases and Related Health Problems, 10th revision, edition 2010. Malta: World Health Organization; 2010:31-77.

24. Lhatoo SD, Johnson AL, Goodridge DM, MacDonald BK, Sander JW, Shorvon SD. Mortality in epilepsy in the first 11 to 14 years after diagnosis: multivariate analysis of a long-term, prospective, populationbased cohort. Ann Neurol 2001;49:336-344.

25. Cockerell OC, Johnson AL, Sander JW, Hart YM, Goodridge DM, Shorvon SD. Mortality from epilepsy: results from a prospective population-based study. Lancet 1994;344:918-921.

26. World Health Assembly. Report of the Conference for the Sixth Decennial Revision of the International Lists of Diseases and Causes of Death. Available at: http://www.who. int/iris/handle/10665/97657\#sthash.p4SzcOB9.dpuf. Accessed June 23, 2014.

27. Hitiris N, Mohanraj R, Norrie J, Brodie MJ. Mortality in epilepsy. Epilepsy Behav 2007;10:363-376.

28. Bender R, Lange S. Adjusting for multiple testing: when and how? J Clin Epidemiol 2001;54:343-349.

29. Abeysekera WWM, Sooriyarachchi MR. Use of Schoenfeld's global test to test the proportional hazards assumption in the Cox proportional hazards model: an application to a clinical study. J Natl Sci Found Sri 2009;37:41-51.

30. Sillanpaa M, Shinnar S. Long-term mortality in childhood-onset epilepsy. N Engl J Med 2010;363: 2522-2529.

31. Tellez-Zenteno JF, Ronquillo LH, Wiebe S. Sudden unexpected death in epilepsy: evidence-based analysis of incidence and risk factors. Epilepsy Res 2005;65:101-115.

32. Tomson T, Nashef L, Ryvlin P. Sudden unexpected death in epilepsy: current knowledge and future directions. Lancet Neurol 2008;7:1021-1031.

33. Lozano R, Naghavi M, Foreman $\mathrm{K}$, et al. Global and regional mortality from 235 causes of death for 20 age groups in 1990 and 2010: a systematic analysis for the Global Burden of Disease Study 2010. Lancet 2012;380: 2095-2128.

34. Gaitatzis A, Sisodiya SM, Sander JW. The somatic comorbidity of epilepsy: a weighty but often unrecognized burden. Epilepsia 2012;53:1282-1293.

35. Office for National Statistics. Statistical Bulletin: Life Expectancy at Birth and at Age 65 by Local Areas in England and Wales, 2011-13. Available at: http://www.ons.gov.uk/ons/rel/ subnational-health4/life-expectancy-at-birth-and-at-age-65-bylocal-areas-in-england-and-wales/2011-13/stb-life-expectancyat-birth-2011-13.html\#tab-National-life-expectancy. Accessed June 19, 2015.

\section{This Week's Neurology ${ }^{\circledR}$ Podcast}

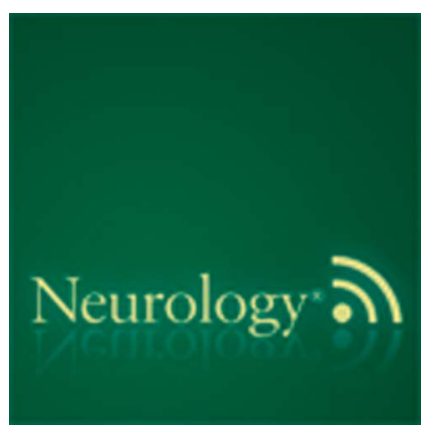

Late diagnosis of cerebral folate deficiency: Fewer seizures with folinic acid in adult siblings (see the February 2016 issue of Neurology ${ }^{\circledR}$ Genetics)

This podcast begins and closes with Dr. Robert Gross, Editor-inChief, briefly discussing highlighted articles from the February 23, 2016, issue of Neurology. In the second segment, Dr. Nathan Fountain talks with Dr. Dave Dyment about his Neurology: Genetics paper on late diagnosis of cerebral folate deficiency. Dr. Ilena George reads the e-Pearl of the week about stroke-like migraine attacks after radiation therapy (SMART) syndrome. In the next part of the podcast, Dr. Ted Burns focuses his interview with Dr. John Hardy on a Neurology Today ${ }^{\circledR}$ story about unraveling the genetics of Alzheimer disease and attending the "Oscars of science."

Disclosures can be found at Neurology.org.

At Neurology.org, click on "RSS" in the Neurology Podcast box to listen to the most recent podcast and subscribe to the RSS feed.

No CME will be offered this week: Interviews based on articles from Neurology ${ }^{\circledR}$ Clinical Practice, Neurology: Genetics, and Neurology ${ }^{\circledR}$ Neuroimmunology \& Neuroinflammation are excluded from the CME program. 


\section{Neurology}

Cause of death and predictors of mortality in a community-based cohort of people with epilepsy

Mark R. Keezer, Gail S. Bell, Aidan Neligan, et al.

Neurology 2016;86;704-712 Published Online before print January 15, 2016

DOI 10.1212/WNL.0000000000002390

This information is current as of January 15, 2016

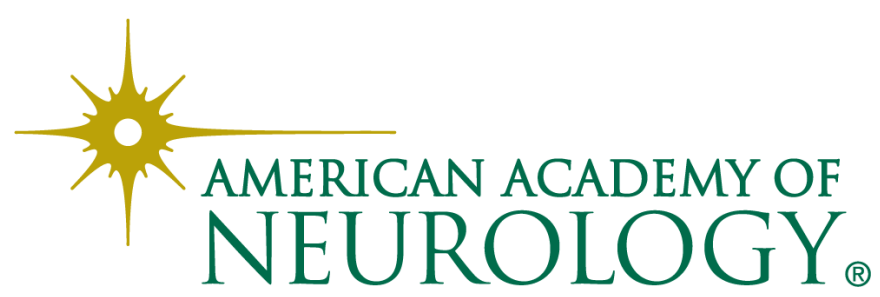




\section{Updated Information \& Services}

\section{Supplementary Material}

\section{References}

Citations

Subspecialty Collections

\section{Permissions \& Licensing}

\section{Reprints}

including high resolution figures, can be found at:

http://www.neurology.org/content/86/8/704.full.html

Supplementary material can be found at:

http://www.neurology.org/content/suppl/2016/01/15/WNL.0000000000 002390.DC1

http://www.neurology.org/content/suppl/2016/01/15/WNL.0000000000 002390.DC2

This article cites 29 articles, 4 of which you can access for free at: http://www.neurology.org/content/86/8/704.full.html\#\#ref-list-1

This article has been cited by 6 HighWire-hosted articles: http://www.neurology.org/content/86/8/704.full.html\#\#otherarticles

This article, along with others on similar topics, appears in the following collection(s):

\section{All epidemiology}

http://www.neurology.org//cgi/collection/all_epidemiology

All Epilepsy/Seizures

http://www.neurology.org//cgi/collection/all_epilepsy_seizures

Natural history studies (prognosis)

http://www.neurology.org//cgi/collection/natural_history_studies_prog nosis

\section{Risk factors in epidemiology}

http://www.neurology.org//cgi/collection/risk_factors_in_epidemiology

Information about reproducing this article in parts (figures,tables) or in its entirety can be found online at:

http://www.neurology.org/misc/about.xhtml\#permissions

Information about ordering reprints can be found online: http://www.neurology.org/misc/addir.xhtml\#reprintsus

Neurology ${ }^{\circledR}$ is the official journal of the American Academy of Neurology. Published continuously since 1951 , it is now a weekly with 48 issues per year. Copyright @ 2016 American Academy of Neurology. All rights reserved. Print ISSN: 0028-3878. Online ISSN: 1526-632X.

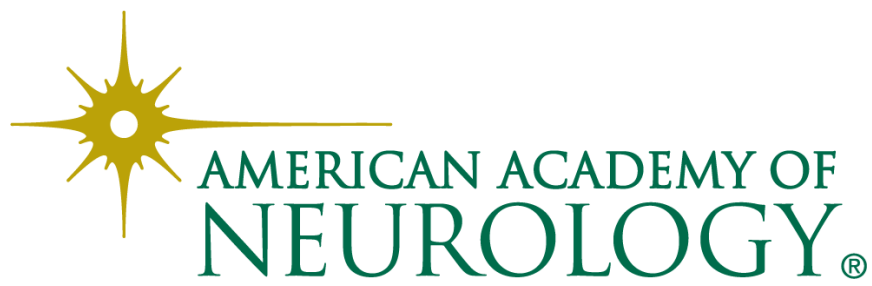

